\title{
Ladies in waiting: the timeliness of first trimester services in New Zealand
}

\author{
Martha Silva ${ }^{1 *}$, Rob McNeill², Toni Ashton ${ }^{3}$
}

\begin{abstract}
Background: Termination of pregnancy (TOP) services are a core service in New Zealand. However, compared to other developed countries, TOP services are accessed significantly later in the first trimester, increasing the risk for complications. The aim of this study is to examine the timeliness of access to first trimester TOP services and establish the length of delay between different points in the care pathway for these services.

Methodology: Data were collected from all patients attending nine TOP clinics around the country between February and May 2009 ( $N$ = 2950). Patient records were audited to determine the timeline between the first point of entry to the health system to the date of termination. In addition, women were invited to fill out a questionnaire to identify personal level factors affecting access to services ( $N=1086$, response rate $=36.8 \%$ ).

Results: Women waited an average of almost 25 days between the date of the first visit with the referring doctor and the date of their termination procedure. There was a delay of 10 days between the first visit with the referring doctor and the date that the appointment for the procedure was booked, and a further 10 days delay between the date the appointment was booked and the first appointment date. Over half of the women in this study had their pregnancy terminated at ten weeks or above.

Conclusion: Women in New Zealand are subject to a lengthy delay while seeking TOP services. Efforts should be made by TOP clinics as well as referring doctors to reduce the waiting times for this service.
\end{abstract}

\section{Introduction}

Termination of pregnancy (TOP) services are a core service in New Zealand, accessed by a large proportion of the female population. National statistics indicate that approximately one quarter of all pregnancies in the country end with a TOP, and one in every four women undergoes a TOP in her lifetime [1]. With an induced pregnancy termination rate of 19.7 per thousand women of reproductive age, New Zealand joins the United States and the United Kingdom among the countries with high induced pregnancy termination rates [1,2].

Although TOP is a safe procedure when conducted under hygienic conditions by a trained provider, the risk for clinical complications increases with gestational age [3-6]. Studies in the USA and Denmark found that abortion-related mortality increases exponentially with additional weeks of gestation, and women who have an induced abortion in their second trimester are

\footnotetext{
*Correspondence: m.silva@auckland.ac.nz

${ }^{1}$ Senior Research Fellow, Health Systems, School of Population Health, University of Auckland, Private Bag 92019, Auckland 1142, New Zealand
}

significantly more likely to die of related causes compared to women who had the procedure before or at 8 weeks [3]. Given the evidence in favour of reducing the gestational age at termination, countries such as The United Kingdom have developed official guidelines that not only address clinical and technical issues, but also guide referral systems to help ensure the best clinical outcomes for their patients. The UK guidelines recommend that services offer arrangements to minimize delay in an attempt to minimize complications associated with later TOP procedures. To this end, they recommend that women requesting TOP ideally be offered an assessment appointment within 5 days of referral and no later than 2 weeks from referral, and be able to undergo a TOP procedure within 7 days and no longer than 2 weeks after the decision to proceed has been made. These guidelines state that no woman should wait longer than 3 weeks from her initial referral to the time of TOP [7].

In New Zealand, although $87.1 \%$ of TOPs are conducted during the first trimester, the average gestational 
age at termination is relatively late within the first trimester [8]. Currently it is unknown why TOP services are delivered relatively late in New Zealand, yet there is international consensus that once a TOP is indicated or has been chosen by a woman, the earlier the procedure, the better the clinical and psychological outcomes for the woman. In the UK in 2006, most TOPs (68\%) took place before ten weeks gestation and a further $22 \%$ took place from 10-12 weeks [9]. In the US in 2001, 59.2\% of TOP occurred before the ninth week of gestation, with an additional 19.3\% before week ten [2]. In Western Australia in $2004,71 \%$ of TOP had taken place before the ninth week of gestation and $86.6 \%$ had occurred by the tenth week [10]. In New Zealand, in 2005 only $17.1 \%$ of women who had a TOP did so by week 8 gestation, and only $54.8 \%$ by week 10 . The remainder $45.2 \%$ received TOP services at 11 weeks gestation or later [8]. TOP performed at a later gestational age have implications for the New Zealand health system, not only with respect to an increase in risk of post-procedure clinical complications, but also with respect to emotional repercussions for the women involved. Delays in health care delivery are associated with increased psychological stress. For instance, significant levels of anxiety are present in the course of screening programs, especially in the case of patients who are referred for further testing or who experience delays receiving test results [11]. Long waiting times for surgical procedures also have a negative impact on quality of life and psychosocial measures, including worse general health perceptions and raised levels of anxiety [12]. These negative psychological effects have been found just prior to the anticipated surgery, and are still present up to six months post-procedure [13]. So once a procedure has been committed to, barriers to access and service delivery should be minimized to avoid potential negative psychological complications. Studies investigating the psychological effects of waiting for a TOP procedure have not been conducted in New Zealand, yet women accessing these services are often already under great stress and delay in having the TOP procedure contributes to this stress. Therefore minimizing any delays should be a priority.

This study aimed to establish what the average timeline was for seeking termination of pregnancy services in New Zealand. In particular, it documents average waiting times between different steps of the care pathway, as well as women's perceptions of the timeliness of services.

\section{TOP Services in New Zealand}

TOP services in New Zealand are unique. While they are health services provided mostly in public hospital settings by health professionals, the services, institutions and key personnel are legislated and regulated separately under the Contraception, Sterilisation and Abortion Act and the Abortion Supervisory Committee (AbSC).

Termination of pregnancy is legal under specific circumstances and if conducted by certified practitioners in licensed institutions. The Crimes Act (1961) outlines the circumstances under which pregnancy termination is legal in the country [14]. Pregnancies that present a serious danger to the life of a woman, serious danger to the physical or mental health of a woman, pregnancies resulting from incest or sexual relations with guardian, pregnancies in women of mental subnormality, and pregnancies presenting fetal abnormality may all be legally terminated. Rape and extreme ages are not themselves grounds for termination, but are taken into consideration. The Contraception, Sterilisation, and Abortion Act (1977) outlines the process through which a legal pregnancy termination can be sought [15]. Women who experience an unwanted pregnancy must first go to a referring doctor, usually a General Practitioner (GP) or a Family Planning doctor (FP) for a referral to a TOP clinic. Referring doctors will order diagnostic tests such as blood tests, vaginal swabs, and ultrasound scans, which will then be forwarded to the TOP clinic. Women for whom the decision to terminate or continue with a pregnancy is unclear may also be referred to pre-decision counseling. Most referring physicians will liaise with the TOP clinic to book an appointment for the woman, while some clinics also allow women to telephone and request an appointment themselves. In either case, a written referral from a primary care physician is a legal prerequisite for a termination to proceed. Once at the TOP clinic, women must be seen by two certifying consultants, who are physicians certified to assess the case and attest to the fulfillment of all legal requirements to terminate the pregnancy. Most times, one of the two certifying consultants will also be the operating doctor. By law, all women must be offered counseling throughout the process, although the law does not specify that women must receive counseling. However some clinics around the country have organized their services such that all women attending the clinic receive at least one counseling session, while other clinics continue to offer counseling, but do not require all women to see a social worker or counselor. Figure 1 shows an illustration of the care pathway described.

All New Zealand citizens and residents are entitled to publicly funded TOP services, which are generally provided within the public system. Regions who do not have TOP services available within their district health board purchase TOP services from other regions, including a private clinic in Auckland. Unless they are 


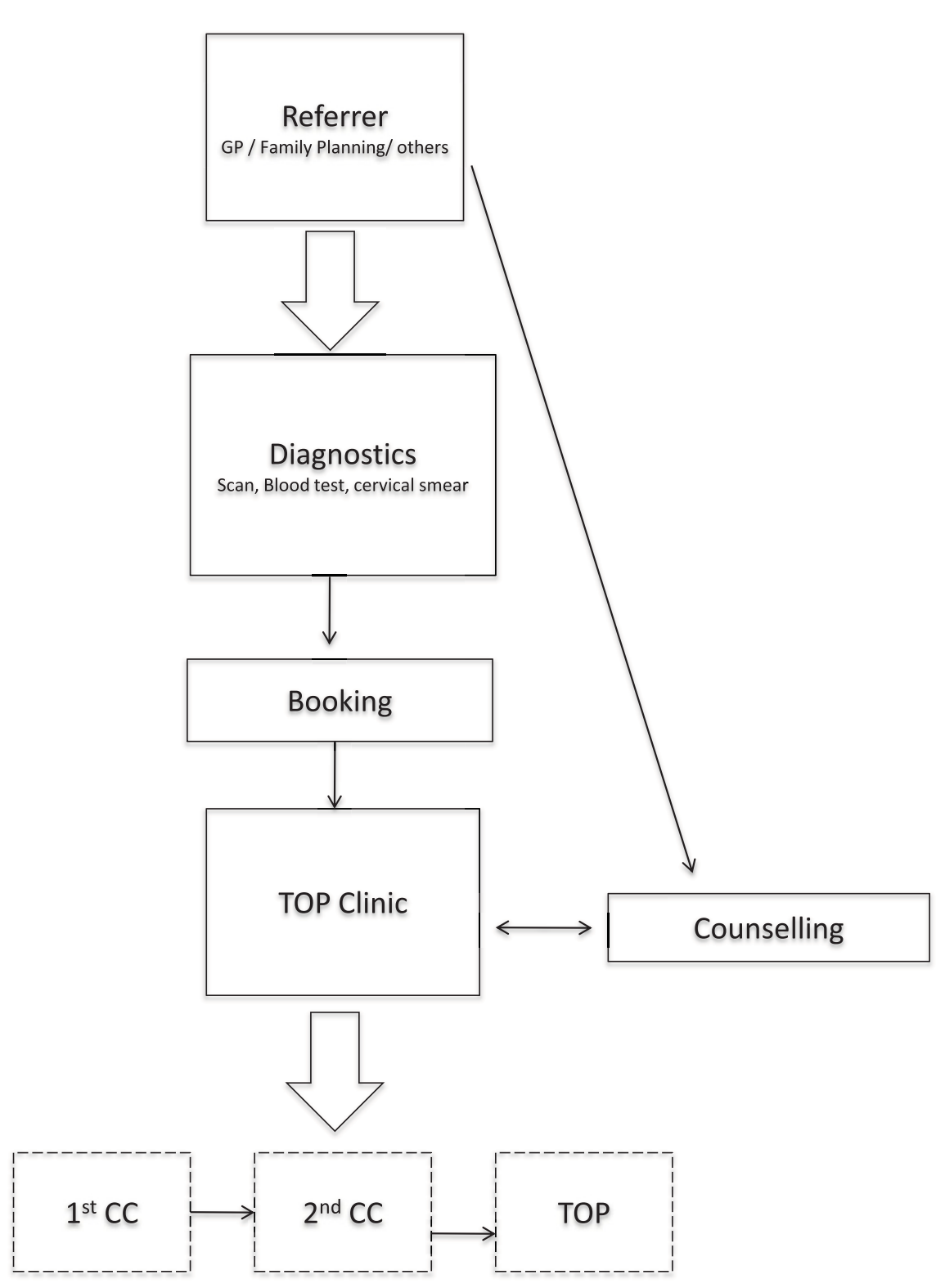

Figure 1 Termination of pregnancy referral and care pathway in New Zealand.

willing to pay for their own TOP procedure, women generally are unable to choose their TOP provider.

\section{Methods}

A mixed methodology was used to investigate the timeliness of first trimester TOP services in New Zealand. Nine first trimester clinics agreed to participate in this study out of a total of thirteen. Four clinics declined participation for various reasons, such as limited staff and lack of time to take on research. One of the nonparticipant clinics was a large specialized centre and the remaining three were smaller day clinics within public hospitals. The first methodology used was an audit of the clinical records of all patients attending participating TOP clinics between February 1st and April 30th 2009 $(\mathrm{N}=2950)$. The nine participating clinics ranged in size from 6 beds per week for TOP services to 140 beds per week and together they account for about $70 \%$ of all TOPs in the country. Eight clinics were on the North Island and one was on the South Island. In order to extract data from the clinical records at participating clinics, research assistants routinely visited the clinics and recorded the required data in a data collection sheet. All patients were assigned a study identification 
number in order to protect their identities. In this way, no identifying information, such as name, address or national health identification number, left the clinic premises.

Secondly, participating clinics invited all women attending their clinics during the study period to participate in a patient questionnaire. Women were given a questionnaire to complete in the waiting room and return to a staff member in a sealed envelope. Out of the 2950 women who attended, 1086 agreed to complete a questionnaire (response rate $=36.8 \%$ ). In order to be able to link the questionnaire information, for those women choosing to complete one, to the audit data, the research team provided study labels to all clinics where the study participant identification number was recorded. Again, this procedure helped ensure that data could be linked while protecting patients' confidentiality. Once outside the clinic premises, no identifiable information was retained.

This study received ethical approval by the MultiRegion Ethics Committee of the Ministry of Health of New Zealand (approval number MEC 08/10/120).

\section{Variables}

At the time of the study, there was no national service guidelines stating the recommended maximum number of days between referral and TOP, as there is in other countries. Throughout this study, delay is defined as the total number of days between each step of the care pathway. For example, the delay between the first contact with the referring doctor and the TOP procedure is the total number of day between the two events. In the case of Medical TOPs, the date of TOP is defined as the date of expulsion of the products of conception. Variables collected through the audit of clinical records included: socio-demographic variables (age, ethnicity, domicile code), parity, gravidity, previous TOPs, date of first contact with referring doctor, date the appointment with the TOP clinic was booked, date of diagnostic tests (ultrasound, blood tests, vaginal swabs), date of counseling appointment, date of first and second certifications, date of termination. When the date of first contact with referrer was not available, the earliest date available from diagnostic tests, referral letter and date when the appointment for the TOP clinics was booked, was taken as proxy. Seven out of the nine clinics had a system in place to record the date that the referring doctor or the patient herself requested an appointment. When this booking date was not available, the earliest date of the date on the referral letter or the date that the referral letter was faxed to the clinic, was taken as proxy.

The patient questionnaire that women were invited to complete included questions about the timing of their decision making process, travel time and transportation partner support, friend and family support, and their perceptions about the timeliness of services.

\section{Results}

Four out of the nine participating clinics provided medical termination of pregnancy (MTOP) as well as Surgical TOPs at the time of the study, and six out of the nine clinics required all patients to see a social worker or counsellor prior to seeing a Certifying Consultant. For the other three clinics, counselling is always offered but entirely optional. Of the 2950 patients seen in participating clinics, 66 (2.2\%) had an MTOP. The remaining women had surgical TOPs.

Table 1 shows a description of the audit sample. Women attending TOP clinics during the study period ranged in ages from 14 to 49 years old, with a mean age of 25 (SD = 7.05). Over fifty percent of the sample was New Zealand European. Most women were referred to the service by a GP. Slightly more than $50 \%$ of women had had a previous TOP, and $33.4 \%$ of the women had had at least two previous TOPs.

Table 1 Characteristics of women attending participating clinics

\begin{tabular}{|c|c|c|}
\hline & Percentages & $\mathrm{N}$ \\
\hline \multicolumn{3}{|l|}{ Age } \\
\hline$<20$ & 28.9 & 2949 \\
\hline $21-25$ & 28.9 & \\
\hline $26-30$ & 18.5 & \\
\hline $31-35$ & 11.7 & \\
\hline $36-40$ & 8.7 & \\
\hline $40+$ & 3.3 & \\
\hline \multicolumn{3}{|l|}{ Ethnicity } \\
\hline NZ European & 52.5 & 2950 \\
\hline Maori & 22.8 & \\
\hline Pacific & 12.3 & \\
\hline Chinese & 5.8 & \\
\hline Other Asian & 7.5 & \\
\hline Other & 11.6 & \\
\hline \multicolumn{3}{|l|}{ Type of referrer } \\
\hline GP & 75.8 & 2936 \\
\hline Family Planning & 17.4 & \\
\hline Other & 6.3 & \\
\hline \multicolumn{3}{|l|}{ Previous TOPs } \\
\hline 0 & 46.5 & 2950 \\
\hline 1 & 20.1 & \\
\hline 2 or more & 33.4 & \\
\hline \multicolumn{3}{|l|}{ Gestational age at TOP } \\
\hline Under 7 weeks 6 days & 11.1 & 2950 \\
\hline 8 weeks 0 days -9 weeks 6 days & 34.7 & \\
\hline Over 10 weeks 0 days & 54.2 & \\
\hline
\end{tabular}


On average, women underwent their TOP procedure at 70 days gestation ( 10 weeks, $\mathrm{SD}=11.3$ ), and this ranged from 35 days for those having an MTOP to 97 days. Only $11.1 \%$ of women had their TOP by the end of the seventh week of pregnancy, and a further $34.7 \%$ had their TOP between the eighth week and the end of the ninth week. The majority of women had a TOP procedure during or after the $10^{\text {th }}$ week of pregnancy.

Table 2 shows the average number of days between different steps in the process of seeking a TOP service. Overall, there was a 24.9 days difference between the first contact with the health care system to procure a TOP and the date of the TOP procedure. An average of 10 days went by between first contact and the date the appointment at the TOP clinic was booked, and another 10 days went by between the date the appointment was booked and the first appointment with the TOP clinic. From the first appointment with the TOP clinic to the date of termination, an average of 4 days went by. Table 3 shows the total delay from the first visit with the referring doctor to the date of termination by gestational age at the time of scan. There is a significant relationship between gestational age at scan and delay to termination (using univariate ANOVA, p-value $<0.001$ ). Women who had a scan under 40 days gestation waited for an average of 26.6. Those who had a scan at 41-60 days gestation waited from an average of 25.9 days. Those who had a scan at 61-80 days waited for an average of 20.6 days, and those having a scan at 81 days or more only waited an average of 12.9 days.

All women who attended participating clinics were asked by the clinic staff if they wanted to fill out a questionnaire as part of the study. This sub sample of women was compared to the complete audit sample to see how representative of this sample they were. Women who answered the questionnaire were not significantly different in age from the complete audit sample, but were significantly different in ethnicity. There were a higher percentage of NZ European and Maori women, the two largest ethnicity groups, in the
Table 3 Average delay by gestational age at the time of scan

\begin{tabular}{lrrr}
\hline \hline Gestation (days) & Delay (days) & N & SD \\
\hline$<40$ & 26.6 & 471 & 11.4 \\
\hline $41-60$ & 25.9 & 1913 & 10.2 \\
\hline $61-80$ & 20.6 & 508 & 9.8 \\
\hline $81+$ & 12.9 & 53 & 10.2 \\
\hline
\end{tabular}

Univariate ANOVA $\mathrm{p}<.0001$

questionnaire sample compared to the audit sample (data not shown).

Women were asked about their decision making process and steps they took before arriving at the TOP clinic (see Table 4). Thirty seven percent of women decided they would have an abortion before or as soon as they thought they were pregnant, and $29.3 \%$ decided as soon as they had a positive pregnancy test, while the remaining $34 \%$ decided some time after they had a positive pregnancy test. A majority of women saw their referring physician for more than one consultation $(64.7 \%)$, and the great majority of these return visits were by the referrer's request. Only $15 \%$ had to reschedule an appointment due to personal circumstances. Slightly more than $50 \%$ of women attended clinics where seeing a counselor or social worker is a non-elective part of the service. Twenty nine percent of women did not see a social worker because they did not want to receive counseling, and surprisingly $3.1 \%$ of women reported they were not offered the opportunity to see a social worker or counselor. Most women reported that finding childcare and taking time off work or study was either not difficult or just a bit difficult, but over $50 \%$ of women found keeping appointments confidential from others to be moderately to very difficult. During the process of seeking TOP services, most women had the full support of their partner as well as family or friends. Twenty one percent of women stated they did not have a partner and $28 \%$ said their friends and family did not know they were pregnant (data not shown).

Table 2 Average number of days delay between different steps of the TOP process

\begin{tabular}{llll}
\hline \hline First contact - booking & $\mathbf{N}$ & Average number of days & $\begin{array}{c}\text { Standard } \\
\text { Deviation }\end{array}$ \\
\hline Booking - counselling & 2949 & 10.3 & 9.1 \\
\hline Booking - $1^{\text {st }}$ Certifying Consultant & 2927 & 10.6 & 7.5 \\
\hline Counselling - $1^{\text {st }}$ Certifying Consultant & 2928 & 10.5 & 7.6 \\
\hline $1^{\text {st }}$ Certifying Consultant - 2 & & 3.1 \\
\hline $2^{\text {nd }}$ Certifying Consultant - TOP & 2402 & 0.4 & 4.2 \\
\hline First contact - 1 & 2422 & 3.2 & 3.3 \\
\hline First contifying Consultant & 2950 & 0.9 & 11.0 \\
\hline
\end{tabular}


Table 4 Women's decision making and process pre TOP

\begin{tabular}{|c|c|c|}
\hline & Percentages & $\mathbf{N}$ \\
\hline \multicolumn{3}{|l|}{ Abortion decision } \\
\hline $\begin{array}{l}\text { Before or as soon as they thought they } \\
\text { were pregnant }\end{array}$ & 37.0 & 1082 \\
\hline $\begin{array}{l}\text { As soon as they had a positive } \\
\text { pregnancy test }\end{array}$ & 29.3 & \\
\hline $\begin{array}{l}\text { Sometime after they had a positive } \\
\text { pregnancy test }\end{array}$ & 33.6 & \\
\hline \multicolumn{3}{|l|}{ Number of consultations with referring doctor } \\
\hline 1 & 35.3 & 1068 \\
\hline 2 & 47.7 & \\
\hline 3 & 13.6 & \\
\hline 4 or more & 6.5 & \\
\hline \multicolumn{3}{|l|}{$\begin{array}{l}\text { Reason for going multiple doctor } \\
\text { consultations }\end{array}$} \\
\hline GP asked & 81.1 & 671 \\
\hline I decided to go more than once & 18.9 & \\
\hline $\begin{array}{l}\text { Patient had to reschedule or change } \\
\text { appointment due to personal circumstances }\end{array}$ & 14.8 & 1069 \\
\hline \multicolumn{3}{|l|}{ Social worker seen for counselling } \\
\hline Yes - I had to & 50.7 & 1079 \\
\hline Yes-I wanted to & 14.1 & \\
\hline No-l did not want to & 28.6 & \\
\hline No-I was not offered & 3.1 & \\
\hline Not yet & 3.5 & \\
\hline
\end{tabular}

Patient feels that have had enough counselling support

\begin{tabular}{lll} 
Yes & 95.4 & 1033 \\
No & 4.6 & \\
\hline Difficulty finding childcare & 37.9 & 602 \\
Not difficult & 22.7 & \\
A bit difficult & 27.4 & \\
Moderately difficult & 12.0 & \\
$\quad$ Very difficult & & \\
\hline Difficulty taking time off from school/work & 29.4 \\
Not difficult & 27.9 \\
A bit difficult & 31.0 & \\
Moderately difficult & 11.7 & \\
Very difficult & & \\
\hline Difficulty keeping appointments confidential & 20.8 \\
Not difficult & 22.4 \\
A bit difficult & 35.6 \\
Moderately difficult & 21.1 & \\
Very difficult & & \\
\hline The time it took to organise the abortion was: & \\
Too long - I wanted an abortion sooner & 37.9 \\
Too long - but I didn't mind waiting & 15.1 \\
Just right & 39.6 \\
Quicker than I wanted & 2.9 \\
Other & 2.0 \\
I still don't know when I'm having the & 2.6 & \\
abortion & & \\
\hline
\end{tabular}

Women were asked to estimate their travel time to the TOP clinic. Patients' travel time ranged from $1 \mathrm{~min}-$ ute to 10 hours, and the average travel time to TOP clinics was 55 minutes $(\mathrm{SD}=70.8)$.

When asked what they thought about the time they had waited to get their TOP: $38 \%$ thought they had waited too long and would have wanted to get the procedure done sooner, $15 \%$ thought it had been too long but they did not mind waiting, almost $40 \%$ said the time they waited was just right, and $2.9 \%$ thought the timing had been too quick.

Women were then asked to provide feedback on the timeliness of services in an open ended question. Women who thought the timing was too long mostly reported that pregnancy symptoms were severe, interfering with everyday life. Women reported that it proved emotionally difficult to experience symptoms for a pregnancy they would ultimately not keep, and maintaining confidentiality was difficult. On the other hand, women who thought the timing had been long but did not mind waiting commented that they were lucky to be getting the service at all, or that it had given them time to think things through. Women who reported that timing was too quick tended to qualify their answer by stating that it was quicker than they expected, not necessarily quicker than they wanted.

\section{Conclusions}

More than fifty percent of women seeking termination of pregnancy services in participating clinics terminated their pregnancy on or after the tenth week of pregnancy, on average waiting twenty five days between the first time they sought care with a referring doctor until the day of their termination. The longest delays in the care pathway were observed equally between the first contact with the referring doctor and the date of booking for the TOP clinic appointment, as well as between the date of booking and the first appointment with the TOP clinic. Once patients had been seen at the TOP clinic, the remaining steps of the care pathway were completed relatively quickly. Women's' perceptions of the length of time they had to wait reflect these delays, with over half stating that the waiting time was too long. For two thirds of the women who responded to the questionnaire, decision making would not have been a factor delaying them in seeking services; yet gestational age ate scan was significantly associated with delay.

Until recently, there were no guidelines in New Zealand outlining what the acceptable timeline for TOP services was. Taking the guidelines of the Royal College of Obstetricians and Gynaecologists [7] (UK), women on average are waiting almost one week more than the recommended maximum time between the first visit 
with their GP or referring doctor to the time of the procedure, which is 3 weeks. In October 2009 The Abortion Supervisory Committee published standards of care for women requesting induced abortions in New Zealand [16]. This document defines as a standard that women must not wait longer than two weeks from the time of referral to the time of the TOP procedure, unless women choose to do so to aid their decision making process. Clinic processes around the country are such that there is no single standard referring process, and therefore the date of referral may be defined differently by different clinics. In some instances, clinics will receive telephone requests for appointments before a referral letter is sent, whereas in other clinics only written referrals are accepted as requests for an appointment to be booked. This document has no mention of what timeline should be considered appropriate between the first contact with a referring doctor regarding an unwanted pregnancy, and referral to a TOP clinic. Women who seek referrals early in pregnancy are at particular disadvantage. Currently there is limited availability of medical termination of pregnancy (MTOP), given that not all clinics offer the services and those who do have small lists. Further introduction of MTOP among all clinics may provide these women with the opportunity of terminating a pregnancy without delay.

Future research in this area should focus on the referrers to TOP services. With about half of the total delay attributed to processes before the time of referral and a large proportion of women indicating that their decision to seek a TOP was immediate, health services researchers must understand what factors are at play in slowing down referrals.

There are several limitations to this study that must be acknowledged. This study was conducted during a single three month time period, and therefore is unable to factor in seasonal variation in unwanted pregnancy rates that affect the waiting times in clinics. Secondly, this study collected information at TOP clinics that pertained to care patients received from referring doctors. In many instances, information about the visits with referring doctors was incomplete or missing, and proxy measures were used. Therefore, the delay data should be considered a conservative estimate of the length of time between the first visit with a referring doctor and the TOP procedure. Thirdly, women were able to decline participation in the questionnaire aspect of the study, leading to self-selection bias. It is impossible to discern whether women who experienced particularly long waiting periods were more likely to participate to voice their frustrations, or whether they were less likely to participate. Despite these limitations, this is the first large scale study of TOP services conducted in New Zealand and highlights the need for a closer attention to women's experiences while accessing these services. To avoid further inequities in service, best practices must be identified to ensure that all clinics, regardless of whether within the public or private sector, can minimize the amount of time women have to wait for a procedure.

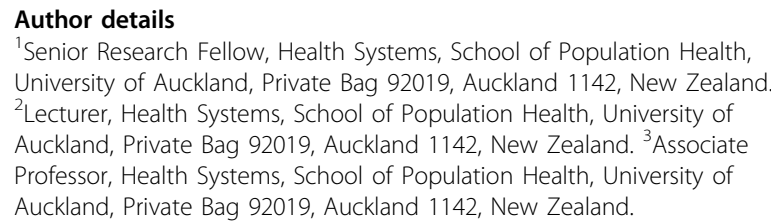

\section{Authors' contributions}

All authors participated in the design and development of the study. MS conducted the data analysis and drafted the manuscript. All authors read, edited and approved the final manuscript.

\section{Competing interests}

The authors declare that they have no competing interests.

Received: 14 December 2009 Accepted: 23 July 2010

Published: 23 July 2010

\section{References}

1. Statistics New Zealand: Abortion trends in New Zealand 1980-2007. Wellington: Statistics New Zealand 2009 [http://www.stats.govt.nz/ publications/populationstatistics/abortion-trends.aspx], Retrieved May 31, 2010.

2. Guttmacher Institute: Facts on Induced Abortion in the United States New York: AGI 2006.

3. Bartlett LA, Berg CJ, Shulman HB, Zane SB, Green CA, Whitehead S, Atrash HK: Risk factors for legal induced abortion-related mortality in the United States. Obstetrics and Gynecology 2004, 103:729-37.

4. Buehler JW, Schulz KF, Grimes DA, Hogue CJ: The risk of serious complications from induced abortions: do personal characteristics make a difference? American Journal of Obstetrics and Gynecology 1985, 153(1):14-20.

5. Ferris LE, McMain-Klein M, Colodny N, Fellows GF, Lamont J: Factors associated with immediate abortion complications. Canadian Medical Association Journal 1996, 154(11):1677-85.

6. Zhou W, Nielsen GL, Moller M, Olsen J: Short-term complications after surgically induced abortions: a register based study of 56117 abortions. ActaObstetrica et Gynecologica Scandinavica 2002, 81:331-336.

7. Royal College of Obstetricians and Gynaecologists: The Care of Women Requesting Induced Abortion London: RCOG Press 2004.

8. Rothwell L, Reid P: Report of the Abortion Supenvisory Committee: 2006 Wellington: New Zealand Parliament 2006.

9. Department of Health: Statistical Bulletin, Abortion Statistics, England and Wales: 20062007 [http://www.dh.gov.uk/prod_consum_dh/groups/ dh_digitalassets/documents/digitalasset/dh_075705.pdf], Retrieved October 1, 2007

10. Department of Health - Government of Western Australia: Induced Abortion in Western Australia 1999-2004: Report of the WA Abortion Notification System 2005.

11. Brett J, Bankhead C, Henderson B, Watson E, Austoker J: The psychological impact of mammographic screening: a systematic review. PsychoOncology 2005, 14(11):917-938

12. Oudhoff JP, Timmermans DRM, Knol DL, Bijnen AB, Van Der Wal G: Waiting for elective general surgery: Impact on health related quality of life and psychosocial consequences. BMC Public Health 2007, 7:164.

13. Sampalis J, Boukas S, Liberman M, Reid T, Dupuis G: Impact of waiting time on the quality of life of patients awaiting coronary artery bypass grafting. CMAJ 2001, 165(4):429-433. 
14. The Crimes Act 1961: Parliamentary Counsel Office.[http://www.legislation. govt.nz/act/public/1961/0043/latest/DLM327382.html ], Accessed on December 11, 2009.

15. Sterilisation and Abortion Act 1977: Parliamentary Counsel Office.[http:// www.legislation.govt.nz/act/public/1977/0112/latest/viewpdf.aspx], Accessed on December 11, 2009.

16. Standards of Care For Women Requesting Induced Abortion in New Zealand: Report of a Standards Committee to the Abortion Supervisory Committee. 2009.

doi:10.1186/1742-4755-7-19

Cite this article as: Silva et al:: Ladies in waiting: the timeliness of first trimester services in New Zealand. Reproductive Health 2010 7:19.

Submit your next manuscript to BioMed Central and take full advantage of:

- Convenient online submission

- Thorough peer review

- No space constraints or color figure charges

- Immediate publication on acceptance

- Inclusion in PubMed, CAS, Scopus and Google Scholar

- Research which is freely available for redistribution

Submit your manuscript at www.biomedcentral.com/submit 